\title{
The Importance of Extravascular Lung Water Measurement in Major Surgeries
}

Çıkar çatışması: Yazarlar çıkar çatısșması bildirmemiștir. Finansal destek: Yazarlar finansal destek almadıklarını bildirmişlerdir. Hasta onamı: Gerek yoktur.

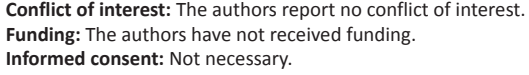

Informed consent: Not necessary.

Cite as: Kansu Kazbek B, Ekmekçi P. Majör cerrahilerde ekstravasküler akciğer sıvısı ölçümünün önemi. GKDA Derg. 2021;27(1):1-13.

öz

Majör cerrahilerde postoperatif pulmoner komplikasyonlar \%1-23 arasında değismekte ve ciddi mortaliteye neden olabilmektedir. Perioperatif ekstravasküler akciğer sIVISI (EVLW) ölçümü, komplikasyonların önlenmesinde olduğu kadar ventilatörden ayırma, sıvı yönetimi ve farmakolojik müdahalelere yanıtın gözlenmesinde de yararlıdır. EVLW akciğerlerde pulmoner damarlar dışında bulunan interstisyel, intrasellüler, alveoler ve lenfatik sıvıyı kapsar. Sağlıklı kişilerde normal değerleri 3-7 ml/kg'dir ve $10 \mathrm{ml} / \mathrm{kg}$ üzerindeki değerlerin pulmoner ödeme ișaret etmektedir. EVLW ölçümünde altın standart gravimetrik yöntem olmakla birlikte, bu yöntemin postmortem uygulanabilmesi nedeniyle ultrasonografi ve transpulmoner termodilüsyon gibi yöntemler geliștirilmiştir. EVLW ölçümü renal replasman tedavisi, ekstrakorporeal membran oksijenizasyonu (ECMO), plevral effüzyonlar ve yüksek PEEP kullanımı gibi durumlardan etkilenebilmektedir. Gelecekte majör cerrahilerde EVLW ölçümünün postoperatif hemodinamik takip ve tedaviye etkilerini araştıracak yeni çalışmalara gereksinim vardır.

Anahtar kelimeler: cerrahi, ekstravasküler akciğer sıvısı, pulmoner ödem

\section{ABSTRACT}

The incidence of postoperative pulmonary complications varies between $1-23 \%$ and these complications can cause serious mortality. Measurement of extravascular lung water (EVLW) is beneficial not only for the prevention of complications but also in weaning, fluid management and monitorization of response to pharmacological interventions. EVLW consists of interstitial, intracellular, alveolar and lymphatic fluid in lungs except for pulmonary vasculature. Its normal range is $3-7 \mathrm{~m} / \mathrm{kg}$ in healthy adults, values greater than $10 \mathrm{ml} / \mathrm{kg}$ point to pulmonary edema. Although the gold standard for measurement of EVLW is the gravimetric method, due to the fact it can only be applied postmortem, measurement methods by using ultrasonography and transpulmonary thermodilution have been developed. EVLW measurement can be affected by renal replacement therapy, extracorporeal membrane oxygenation (ECMO), pleural effusions and high PEEP. New research focusing on the effect of EVLW measurement on postoperative hemodynamic management is necessary in the future.

Keywords: surgery, extravascular lung water, pulmonary edema
Received/Geliş: 24.12 .2020

Accepted/Kabul: 13.01.2021

Published Online/Online yayın: 23.03.2021

Baturay Kansu Kazbek Ufuk Üniversitesi Tıp Fakültesi Anesteziyoloji ve Reanimasyon Anabilim Dalı Ankara - Türkiye

bkkazbek@gmail.com ORCID: 0000-0002-1230-7814

P. Ekmekçi 0000-0002-0057-2338 Ufuk Üniversitesi Tıp Fakültesi Anesteziyoloji ve Reanimasyon Anabilim Dalı Ankara - Türkiye

\section{MAJÖR CERRAHILERDE EVLW NEDEN ÖNEMLIDIR?}

Dünyada yıllık ortalama 230 milyondan fazla majör cerrahi gerçekleştirilmekte ${ }^{[1]}$ ve postoperatif pulmoner komplikasyon oranı \%1-23 arasında değişmektedir ${ }^{[2,3]}$. Postoperatif pulmoner komplikasyonlar artmış postoperatif mortalite ile ilişkilidir ve sıklıkları tanım, ciddiyet ve eşlik eden risk faktörlerine bağlı olarak \%6-80 oranındadır ${ }^{[4]}$. Pulmoner ödem pulmoner komplikasyonlar arasında önemli bir yere sahiptir ve aşırı sıvı yükü, cerrahiye karşı gelişen sistemik inflamatuar yanıt, miyokard iskemisi, kan transfüzyonu gibi nedenlerle sıvının interstisyuma ve alveollere transüdasyonu sonucunda meydana gelebilir ${ }^{[5]}$.

Geçtiğimiz yüzyıllarda pulmoner ödemin erken tanın- 
ması ve tedaviye yanıtın yakın takip edilebilmesine yönelik birçok çalışma yapılmıştır. Bu amaçla kullanılacak yöntemin ideal özellikleri arasında, yüksek sensitivite ve spesifite ile klinik belirtilerin ortaya çıkmasından önce ekstravasküler sıvı birikiminin tanıması sayılabilir. Klinisyenler için, ekstravasküler akciğer sıvısının kesin ölçümünün yanı sıra hidrostatik basınç artışı veya permeabilite artışı gibi etiyolojilerin ayırt edilmesi de vazgeçilmezdir ${ }^{[6]}$. Majör cerrahilerde perioperatif ekstravasküler akciğer sıvısı (EVLW) ölçümü, pulmoner ödemin erken tanı ve tedavisinin takibi kadar ventilatörden ayırma (weaning), sIVı yönetimi ve farmakolojik müdahalelere yanıtın gözlenmesi gibi farklı amaçlara yönelik de kullanılmaktadır ${ }^{[7,8]}$.

\section{Tanım ve Fizyoloji}

Fizyolojik olarak, vasküler yapı ve interstisyum arasındaki hidrostatik ve onkotik basınç farkı ile alveolokapiller bariyerin filtrasyon katsayısı tarafından belirlenen normal bir sıvı ve solüt sızıntısı vardır ve Starling yasasının temelini oluşturur. 1940'lı yıllara kadar pulmoner ödem oluşum mekanizması, Starling yasası ile açıklanırken, Danielli ve ark.'nın ${ }^{[6]}$ yaptıkları elektron mikroskopisi çalışmada, endotel yüzeyini kaplayan endotelyal glikokaliks (EG) yapısını tanımlamışlar ve bu bilgiler ışığında pulmoner ödem hakkındaki anlayışımız yeniden şekillenmiştir. Bu yapı, sıvı ve solüt geçişini sınırlarken aynı zamanda plazma proteinlerinin tutunduğu bir iskelet görevi de görmekte ve kan akımından kaynaklanan gerilimin hücre içine iletilmesini sağlayan bir mekanoreseptör gibi davranmaktadır. Bu tabakanın cerrahi travma veya iskemi/reperfüzyon hasarı gibi nedenlerle bozulması permeabiliteyi arttırmaktadır. Normalde, pulmoner dolaşımdan filtre edilen sıvı ile lenfatik sistem tarafından emilen sıvı arasında bir denge vardır. Pulmoner lenfatik sistem $20 \mathrm{ml} / \mathrm{h}$ drenaj yapabilme kapasitesine sahiptir ve kronik interstisyel basınç yüksekliğinde 5 ila 10 kat daha fazla sıvı drene edilebilir ${ }^{[5]}$. Interstisyel kompartmanın düşük kompliansı daha fazla sıvı artışına izin vermez. Bu koruyucu mekanizma proteoglikan tabakasının parçalanmasına bağlı matriks bütünlüğünün bozulması nedeniyle kısa ömürlüdür ve bunun sonucu olan EVLW artışı klinik olarak pulmoner ödem şeklinde bulgu verir.

\section{EVLW normal değerleri nedir?}

Damar dışı akciğer sıvısı, akciğerlerde pulmoner damarlar dışında bulunan interstisyel, intrasellüler, alveoler ve lenfatik sıvıyı kapsar ve sağlıklı kişilerde damar dışı akciğer sıvısının normal değerleri 3-7 ml/ kg'dır. Ancak orta-yüksek riskli cerrahi geçirecek hastalar veya kritik yoğun bakım hastalarında sıklıkla daha yüksek değerler görülür ve bunun nedeni olarak cerrahi stres ve inflamasyon belirtilmiştir. Cerrahi geçiren 687 hasta üzerinde yapılan 19 çalışmadan elde edilen verilere dayanarak bu gruptaki hastalarda en düşük ortalama EVLW değeri $5.4 \pm 1.1 \mathrm{ml} / \mathrm{kg}$, en yüksek ortalama EVLW değeri ise $10.6 \pm 4 \mathrm{ml} / \mathrm{kg}$ (akciğer rezeksiyonu hastalarında) olarak ölçülmüştür ${ }^{[9]}$. Yapılan çalışmalar cut-off değeri olarak $10 \mathrm{ml} / \mathrm{kg}$ üzerindeki değerlerin pulmoner ödeme işaret ettiğini göstermiştir ${ }^{[10]}$.

\section{Ölçüm Yöntemleri nelerdir?}

\section{i. Gravimetrik Yöntem}

EVLW ölçümünde en sensitif ve kesin yöntem gravimetrik ölçümdür. Bu yöntem akciğerlerin çıkartılması ve tartılması prensibine dayanır. Islak ve kuru örneklerin tartılması ile sıvı içeriği ölçülebilir. Kan gibi ölçümü etkileyen faktörler için düzeltmeler standard veriler veya işaretli bir madde kullanılarak yapılabilir. EVLW ölçümünde altın standart olan gravimetrik yöntem yalnızca preklinik modellerde kullanılabilir $^{[11]}$.

\section{ii. Oskültasyon ve Akciğer Grafisi}

Geleneksel olarak kullanılan oskültasyon, Laennec'in 19. yy.'da belirttiği "derin inspiratuar krepitan raller" prensibine dayanmaktadır. Gözlemciler arası değişkenlik, seslerin oluşum mekanizmasının yetersiz anlaşılması, hafif ve orta düzeyde sIVı birikiminin saptanmasında yetersizlik ve sürecin takibinde zorluk gibi ciddi dezavantajları vardır.

Pulmoner ödemin değerlendirilmesinde akciğer gra- 
fisi kullanılan olguların yaklaşık $1 / 3^{\prime}$ inde görüntüler suboptimal olmakta ve tomografi ile uyumluluk göstermemektedir ${ }^{[12]}$. Diğer yöntemlerle karşılaştırıldığında, EVLW ölçümünde bu iki yöntem düşük sensitivite ve spesifite nedeniyle günümüzde tercih edilmemektedir $^{[13]}$.

\section{iii. Akciğer ultrasonografisi}

Akciğer ultrasonografisi EVLW ölçümünde noninvazif, kolay uygulanabilir, gerçek zamanlı, ekonomik olması ve yatak başı uygulanabilmesi sayesinde hızlı tanıya olanak veren bir yöntem olarak öne çıkmıştır [14]. Radyasyon maruziyeti olmaması bu tekniğin önemli bir avantajıdır. Pulmoner ödem, pnömotoraks, plevral effüzyon ve pnömoninin ayırıcı tanısının yapılmasını sağlar, ancak pulmoner ödem etyolojisini aydınlatmakta yetersizdir.

Anterolateral pencereden bakıldığında pulmoner ödemin ultrasonografik tanısında kilit rol oynayan B çizgileri, plevra hattından başlayan ve ekranın uzak kenarına doğru giden sınırları belirgin hiperekoik artefaktlardır ve alveollerden veya sıvı nedeniyle kalınlaşmış interlobüler septalardan kaynaklanır. B çizgileri normal akciğerlerde gözlenmez ve EVLW artışına işaret eder. B çizgilerinin sayısına göre akciğer ultrasonografisinde yarı kantitatif bir skorlama yapılabilir ve $>30$ B çizgisi varlığı ciddi EVLW artışını düşündürür[ ${ }^{15]}$ (Tablo 1).

\section{Tablo 1. B çizgisi sayısına göre EVLW artşı ve} skorlama $^{[15]}$

\begin{tabular}{lcc} 
Skor & B çizgisi sayısı & EVLW artışı \\
\hline 0 & $\leq 5$ & Yok \\
1 & $6-15$ & Hafif \\
2 & $16-30$ & Orta \\
3 & $>30$ & Ciddi \\
\hline
\end{tabular}

Akciğer ultrasonunun torasik ve akciğer transplantasyonu cerrahilerinde kullanılması üzerine Assaad ve ark. ${ }^{[7]}$, akciğer ultrasonografisi bazlı yarı kantitatif algoritmaların EVLW takibinde ve postoperatif yönetimde faydalı olacağını bildirmişlerdir.

Ultrasonografi ile B çizgilerinin değerlendirilmesinde cerrahi manipülasyonlar, hasta pozisyonu ve görüntülenen akciğerin dependan oluşu $\mathrm{B}$ çizgilerinin sayısını etkileyecektir. Bu nedenle USG ile EVLW takibinde bir kılavuz rehberliğinde tekrarlanan değerlendirmeler yapılması önemlidir.

\section{iv. Manyetik Rezonans Görüntüleme}

Manyetik rezonans görüntülemesinde son zamanlarda kaydedilen ilerlemeler, rejyonel ventilasyon, perfüzyon, ventilasyon/perfüzyon eşleşmesi ve akciğer sıvısı gibi parametrelerin ölçümünü sağlamıştır. Bu alandaki çalışmalar spin-eko sekanslarının hayvanlarda akciğer sıvısını gravimetrik yöntemle korele olacak şekilde ölçebilmesi prensibine dayanmaktadır. Bununla birlikte, MR ile akciğer sıvısının \%4-5 oranında düşük ölçülebileceğini belirtmek gerekir ${ }^{[16]}$. Yakın zamanda geliştirilen HASTE protokolü, kalp yetmezliği hastalarında akciğer sıvı içeriğinin sol ventrikül diastol sonu basıncı ile korele edilebilmesini sağlamıştır ${ }^{[17]}$.

Bu tekniğin avantajları arasında noninvazif olması ve iyonize radyasyona maruziyet olmaması sayılabilir. Ek olarak farklı kontrast ajanları kullanılarak artmış hidrostatik basınca bağlı proteinden fakir ekstravasküler sıvı ile artmış vasküler permeabiliteye bağı proteinden zengin ekstravasküler sıvı ayrımı yapılabilmektedir ${ }^{[18]}$. Tekniğin dezavantajları arasında yüksek maliyet, hasta transferi ile ilgili zorluklar ve kaliteli görüntü elde etmenin zor olması gibi noktalar sayılabilir.

\section{v. Bilgisayarlı Tomografi}

Bilgisayarlı tomografide pulmoner ödem, buzlu cam manzarası, plevral efüzyon, vasküler çaplarda artma ile interlobüler septalar, peribronkovasküler interstisyum ve fissürlerde kalınlaşma şeklinde bulgu verir. Bu yöntemde akciğer sıvısının ölçümü kalp ve büyük damarlar dışındaki toplam sıvı miktarının hesaplanması prensibine dayanır ve uzun yıllar akciğer sIVISInın ölçümünde kullanılmıştır.

Tomografi ile EVLW ölçümü, koyunlarda akut akciğer hasarı modelinde yapılan gravimetrik ölçümler ile iyi korelasyon göstermektedir ${ }^{[19]}$. Benzer şekilde ARDS hastalarında yapılan termodilüsyon çalışmaları ${ }^{[20]}$ ve 

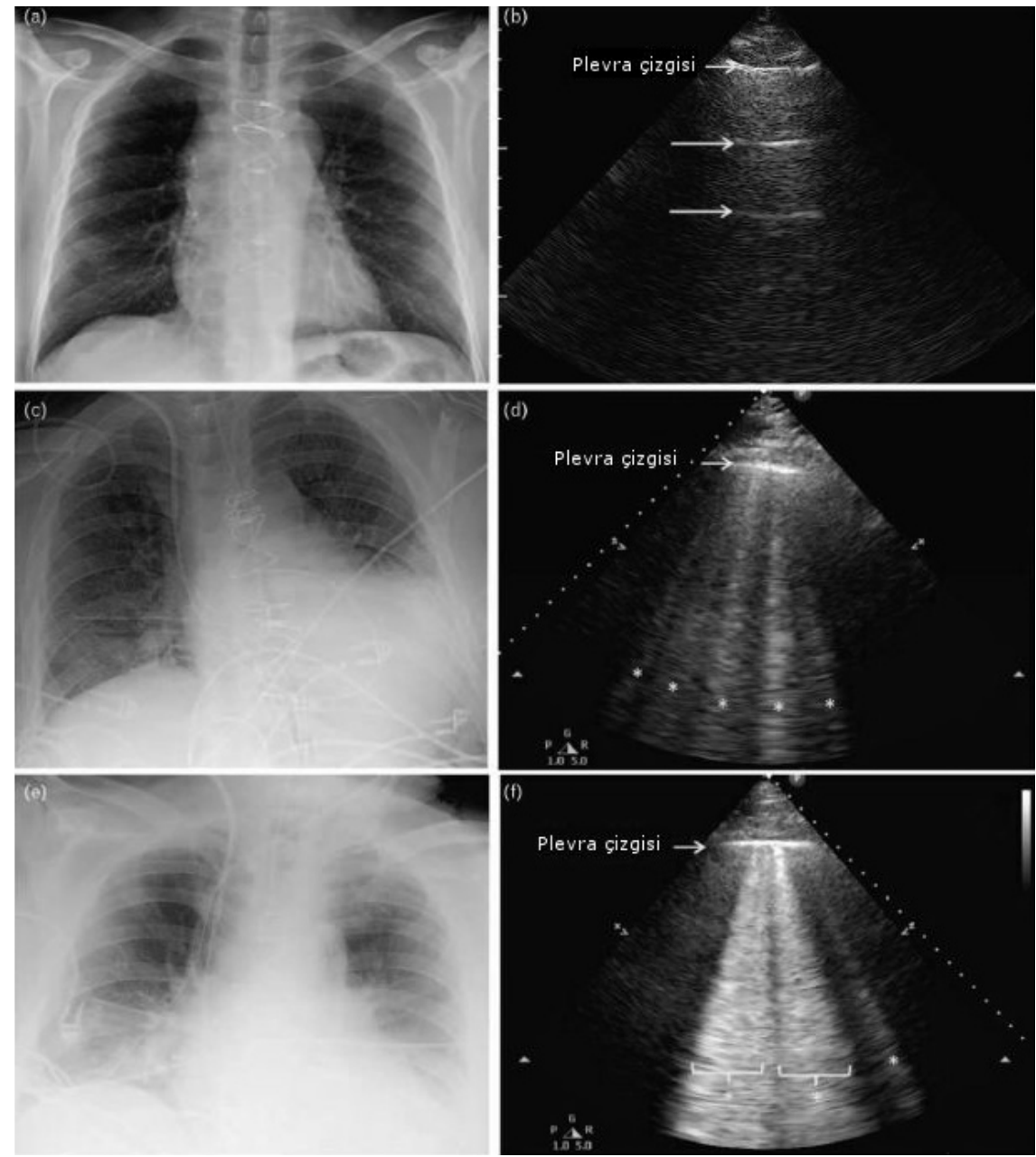

Figür 1. Posteroanterior akciğer grafisi ve ultrasonografide B çizgilerinin korelasyonu.

köpeklerde yapılan kardiyojenik ve nonkardiyojenik ödem modellerinde ${ }^{[21]} \mathrm{EVLW}$ ölçümü ile gravimetrik yöntemlerin korelasyonu belirtilmiştir. Benzer şekilde, akciğer ödeminde direkt grafiler ile bilgisayarlı tomografi korelasyonunu inceleyen çalışmalar da vardır ${ }^{[22]}$.

\section{vi. Pozitron Emisyon Tomografisi}

Bu yöntemde anlamlı bir EVLW artışından söz edebilmek için \%6-12'lik bir artış gereklidir ${ }^{[23]}$. Schuster ve ark. pozitron emisyon tomografisinin (PET) insanlarda güvenilir şekilde EVLW ölçümünde kullanılabileceğini belirtmişlerdir ${ }^{[24]}$. Her ne kadar PET, EVLW ölçümünde görece olarak hassas olsa da yüksek maliyet ve iyonize radyasyona maruziyet nedeniyle kullanımı kısıtlıdır.
Pozitron emisyon tomografisinde (PET), iki farklı işaretli molekül kullanılarak ölçüm yapılır. İlk aşamada metabolik olarak inert olan $\mathrm{H}_{2}^{15} \mathrm{O}$ intravenöz olarak verilir ve bu molekülün intravasküler ve ekstravasküler kompartmanlar arasında yayılması ile toplam akciğer sıvısı hesaplanır. Daha sonra hastanın düşük konsantrasyonda $\mathrm{C}^{15} \mathrm{O}$ inhale etmesi sağlanır. $\mathrm{Bu}$ molekül, hemoglobine bağlanır ve intravasküler volümün hesaplanmasında kullanılır. Son olarak, intravasküler akciğer sıvısının toplam akciğer sıvısından çıkartılması ile EVLW hesaplanabilir ${ }^{[25]}$.

\section{vii. Empedans teknikleri}

Akciğer sıvısının ölçümünde empedans tekniklerinin kullanımı, hava ve sıvının akıma farklı seviyelerde direnç göstermesi prensibine dayanır. İntratorasik 


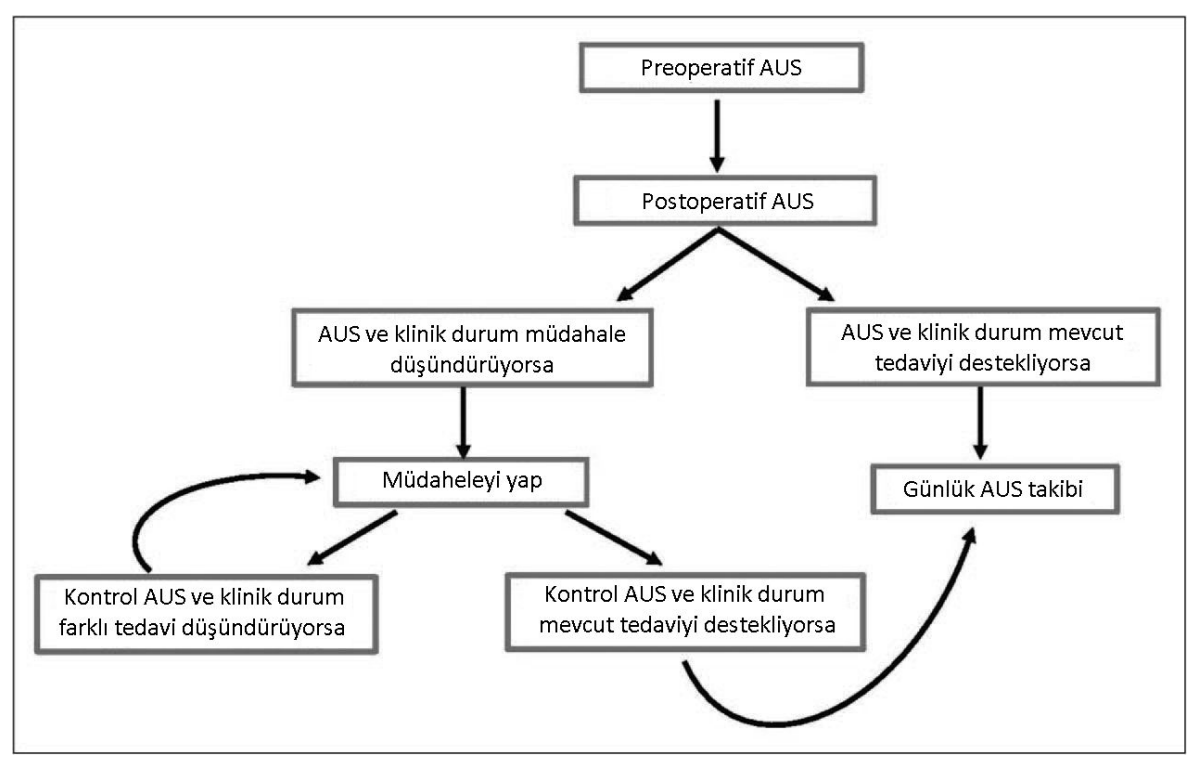

Figür 2. Akciğer ultrasonografisi (AUS) bilateral değerlendirilmeli, preoperatif bazal AUS yapılmalıdır. Postoperatif erken dönemde ve günlük veya klinik gereksinim durumunda AUS tekrarlanmalıdır. Klinik değişiklikler AUS ile takip edilmelidir ${ }^{[7]}$.

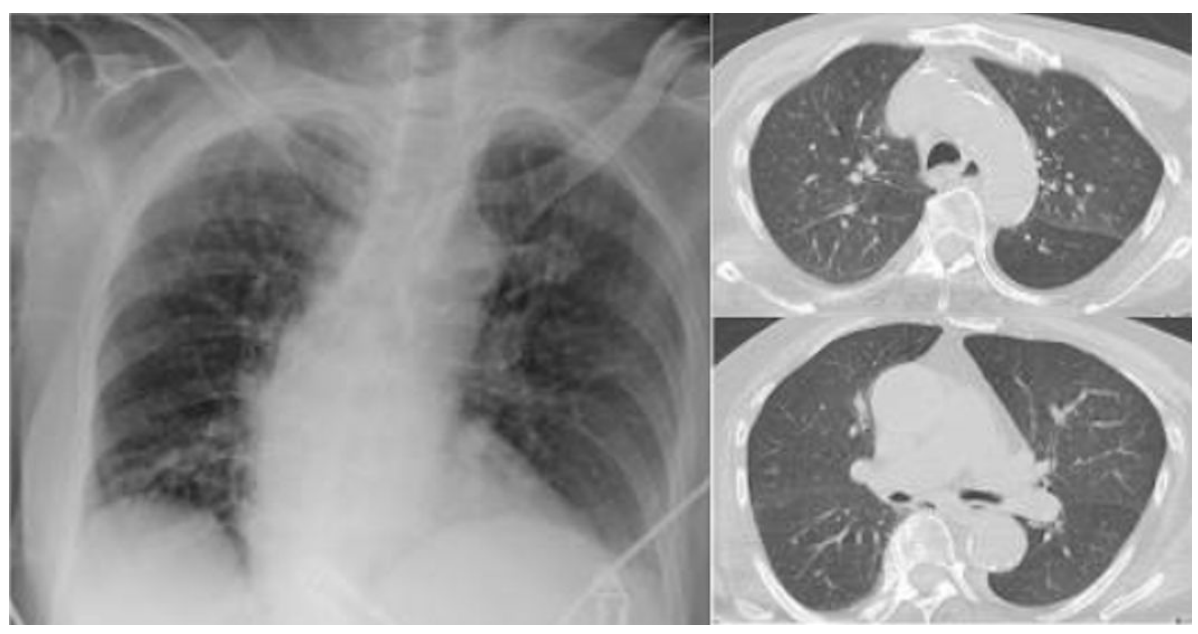

Figür 3. Akciğer ödemine ait direkt grafi (sol) ve bilgisayarlı tomografi (sağ) görüntüleri[22].

sıvı miktarı arttıkça akciğerin elektriksel iletkenliği artar ve empedans azalır ${ }^{[26]}$. Bununla birlikte, empedans, EVLW'nin direkt bir ölçümü olmaktan ziyade total pulmoner sıvının ölçütüdür.

Empedans, internal veya eksternal cihazlar kullanılarak ölçülebilir. Yakın zamanda yapılan çalışmalar, ambulatuar ölçüme olanak sağlaması nedeniyle internal ölçümlere odaklanmaktadır.

Koyunlarda yapılan bir çalışma, intratorasik empe- dans ölçümlerinin termodilüsyon bazlı EVLW ölçümleri ile korelasyon gösterdiğini ortaya koymuştur ${ }^{[27]}$. Buna ek olarak köpekler üzerinde yapılan bir çalışmada, intratorasik empedans ile sol ventrikül enddiastolik basıncı arasında bir korelasyon olduğu gösterilmiştir ${ }^{[28]}$. Bu korelasyonun klinik önemi, kalp yetmezliği hastalarında implante pacemaker kullanarak ölçülen empedansın dekompansasyon semptomlarından 15 gün önce \%12 oranında düştüğünün gösterilmesi ile daha belirgin hâle gelmiştir ${ }^{[29]}$ 


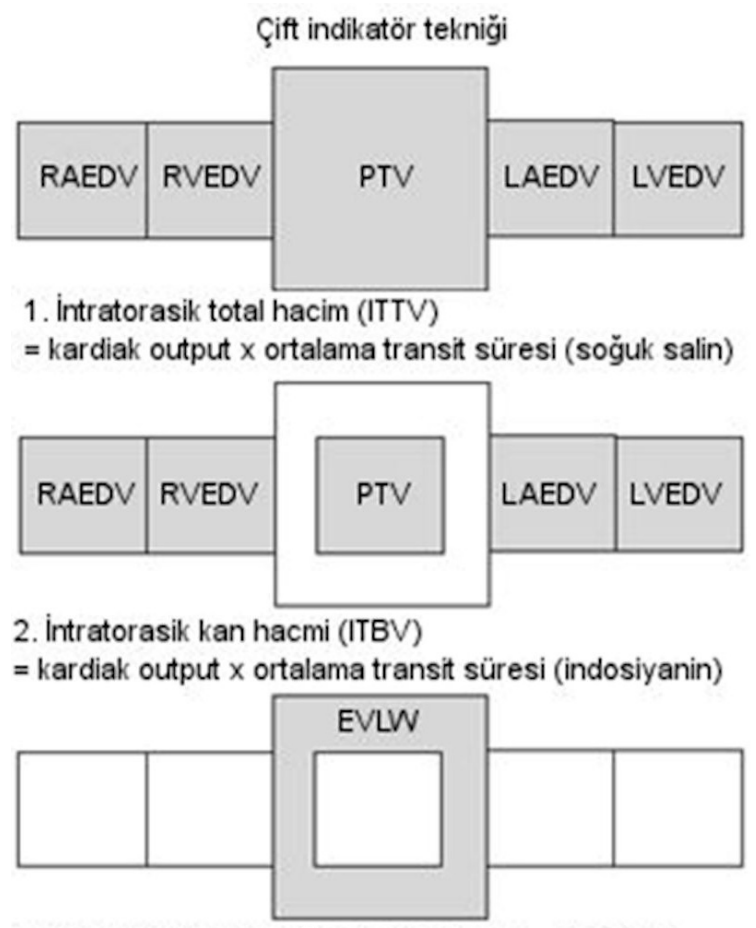

\section{Ekstravasküler akciğer sivisI (EVLW) $=$ ITTV-ITBV}

Figür 4. Çiftli indikatör tekniğiyle EVLW hesaplanması.

viii. Termodilüsyon tekniği

Indikatör dilüsyon metodları dolaşıma indikatör enjekte edilmesi ve daha sonra konsantrasyonlarının ölçülmesi prensibine dayanır. Çift indikatör metodunda soğuk salin infüzyonu ve indosiyanin yeşili kullanılır ve soğuk salin total intratorasik hacimde (ITTV) dağılırken indosiyanin yeşili intratorasik kan hacmi (ITBV) içerisinde yayılır. ITBV içerisinde pulmoner vasküler yatak yer alırken TITV içerisinde akciğerlerin ekstravasküler veya interstisyel hacmi yer alır.
Bu iki hacim arasındaki farktan yola çıkarak EVLW hesaplanabiliri[30] (Figür 4). Bu yöntem, zaman alması ve pahalı olması nedeniyle yerini tekli indikatör tekniğine bırakmıştır ve bu metotta dolaşıma yalnızca soğuk salin bolusu verilir.

Günümüzde tekli indikatör yöntemiyle transpulmoner termodilüsyon (TPTD) ölçümü için kullanılan $\mathrm{PiCCO}^{\circledR}$ ve $\mathrm{EV} 1000^{\circledR}$ sistemi olmak üzere 2 benzer ticari sistem vardır (Figür 5). Termal indikatörün kullanıldığı TPTD metodunda pulmoner termal volüm (PTV), böylece, $C O$ ve inen kısım süresi (Dt) kullanılarak hesaplanabilir. ITTV, PTV ile non-pulmoner bölümlerin termal volümlerinin toplamına eşittir. Non-pulmoner termal bölümler ise kalp odacıklarındaki kan hacmine eşittir. Bu odacıklar diastol sonunda en geniş hâllerinde olduğundan bu hacme geleneksel olarak global enddiastolik volüm denir (Figür 6).

Transpulmoner indikatör dilüsyon tekniğinin klinik uygulamasında soğuk salin bolusunun sıcaklığı indikatör olarak rol oynar, santral dolaşıma enjekte edilir ve geçişi pulmoner arterde (transkardiyak termodilüsyon) veya distal aortta (transpulmoner termodilüsyon) saptanır. Stewart ve Hamilton tarafından geliştirilen prensiplere dayanarak indikatörün zamana bağı değişimi hesaplanarak kardiyak output hesaplanır ve bir indikatör dilüsyon eğrisi (transit süresine karşı konsantrasyon) oluşturulur ${ }^{[31]}$. Bu eğriden yola çıkarak $\mathrm{CO}$, intratorasik hacimler, EVLW ve pulmoner vasküler permeabilite indeks (PVPI) gibi hemodinamik veriler elde edilebilir. TPTD yöntemi ile
A)

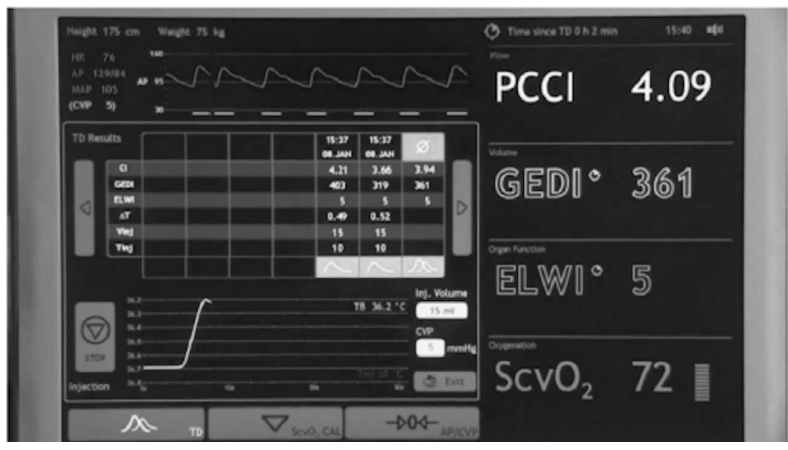

B)

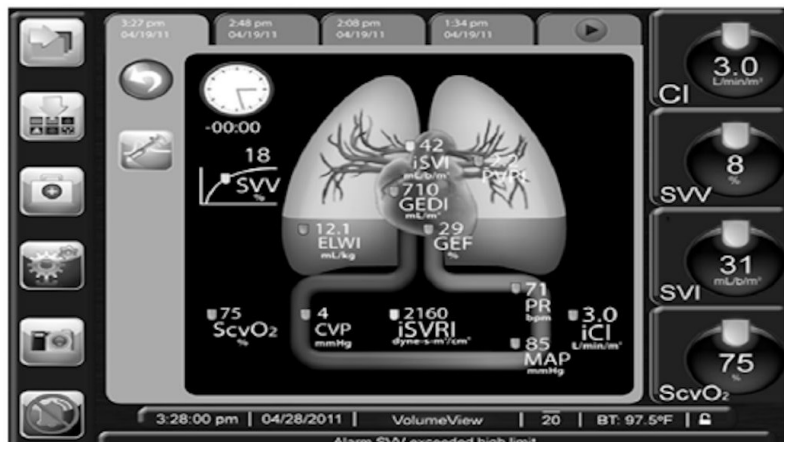

Figür 5. A) PiCCO $^{\circledR}$ sistemi B) EV1000 ${ }^{\circledR}$ sistemi. 


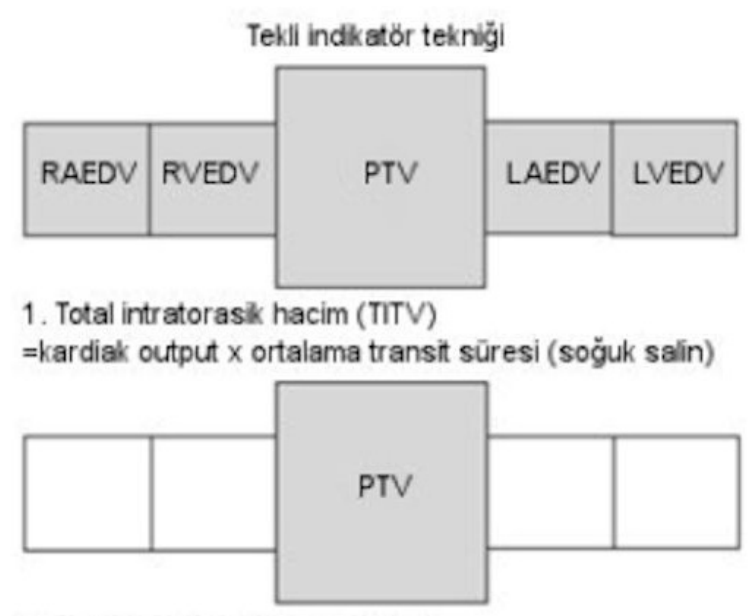

2. Pulmoner termal hacim (PTV) =kardiak output $x$ dilüsyon süresi (soğuk salin)

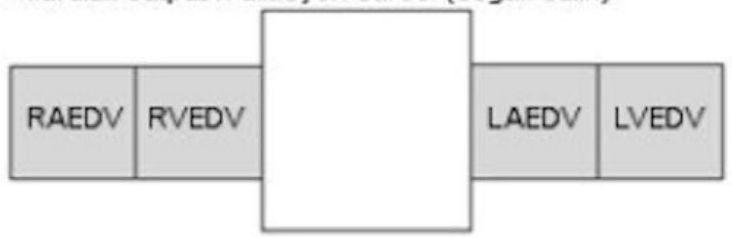

3. Global end-diastolik volüm (GEDV) $=$ TITV - PTV

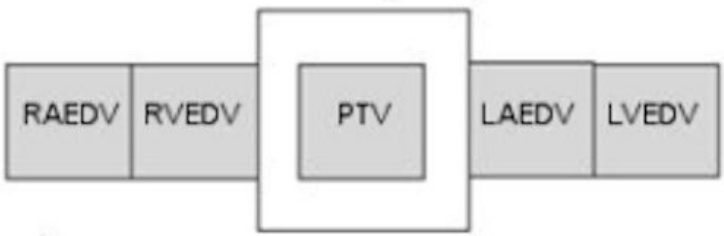

4. Intratorasik kan hacmi (ITBV) $=(1.25 \times$ GEDV $)-28.4$

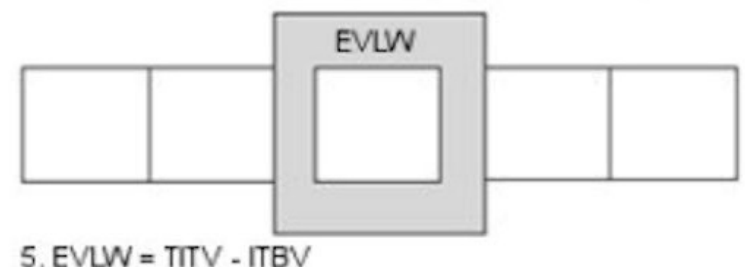

Figür 6. Tekli indikatör yöntemi.

EVLW ölçümünün yakın zamana kadar en önemli kısıtlamalarından biri, kardiyak fonksiyonu bozuk hastalardaki güvenilirliği olmuştur. Hilty ve ark. tarafından yapılan bir çalışmada, TPTD ölçümlerinin ventrikül boyutu ve çıkım yolu obstrüksiyonundan etkilenmediği gösterilmiştir ${ }^{[21]}$.

$\mathrm{PiCCO}^{\circledR}$ sistemi ile EVLW ölçümü hayvan çalışmalarında, altın standart olan gravimetrik yöntem ile karşılaştırılmış ve geçerliliği kanıtlanmıştır ${ }^{[32]}$.
Termodilüsyon ile EVLW ölçümü normal akciğerlerde, kardiyojenik pulmoner ödemde ve ARDS modellerinde kesinlik göstermektedir. Yapılan bir insan otopsi çalışmasında, EVLW ile postmortem akciğer ağırlığı arasında kesin bir korelasyon gösterilmiştir ${ }^{[33]}$. Benzer şekilde, yakın zamanda beyin ölümü gerçekleşmiş hastalar üzerinde yapılan bir çalışmada, TPTD yöntemi ile ölçülen EVLW değerlerinin gravimetri ile yakın korelasyon gösterdiği bildirilmiştir ${ }^{[20]}$.

\section{Majör cerrahilerde EVLW}

EVLW ölçümü yakın zamana kadar ARDS ve septik şok hastalarının yoğun bakımdaki tanı ve tedavisinde kabul gören bir yöntem olsa da, günümüzde yüksek riskli cerrahilerde perioperatif pulmoner ödemin ve akut akciğer hasarının erken tespiti ve ayırıcı tanısının yapılmasında değerli bir yöntem hâline gelmiştir ${ }^{[34]}$. PVPI ve EVLW'nin birlikte ölçümü ile pulmoner ödem etiyolojisinin ayırt edilmesi ve sıvı yönetimi ile farmakolojik tedavinin bu bilgiler ışığında yönlendirilmesi olası olmaktadır ${ }^{[10]}$ (Figür 7).

\section{i. Kardiyak cerrahi}

Kardiyak ve majör vasküler cerrahi, artmış kapiller permeabilite ile karakterize olan sistemik inflamatuar yanıt ve ALI/ARDS'ye neden olabilir ${ }^{[35]}$. Bypas cerrahisi geçiren hastaların \%30-50'sinde görülebilen bu durum postoperatif uzamış mekanik ventilasyona neden olabilir ${ }^{[36]}$. Bu hasarlanmanın proinflamatuar yanıtlardan kaynaklandığı düşünülmektedir ve gaz değişiminde geçici bozukluklar ve mekanik anormalliklerle seyreden EVLW artışına neden olurlar ${ }^{[37]}$. Akciğerde vasküler hasarlanmaya neden olan diğer faktörler arasında cerrahi travma ve kan transfüzyonu sayılabilir.

Elektif kardiyak cerrahi sonrası yoğun bakımda mekanik ventilasyon uygulanan 26 hasta üzerinde yapılan bir çalışmada, EVLW değeri 10 ve üzerinde olan hastalarda plazma onkotik basıncının daha düşük olduğu ve mekanik ventilasyon süresinin \%20 oranında uzadığı gösterilmiştir ${ }^{[38]}$. Elayashy ve ark.'nın ${ }^{[39]}$ kardiyopulmoner bypas geçiren 60 çocuk üzerinde yaptığı bir çalışmada, baypas sonrası artan EVLW'nin ultra- 


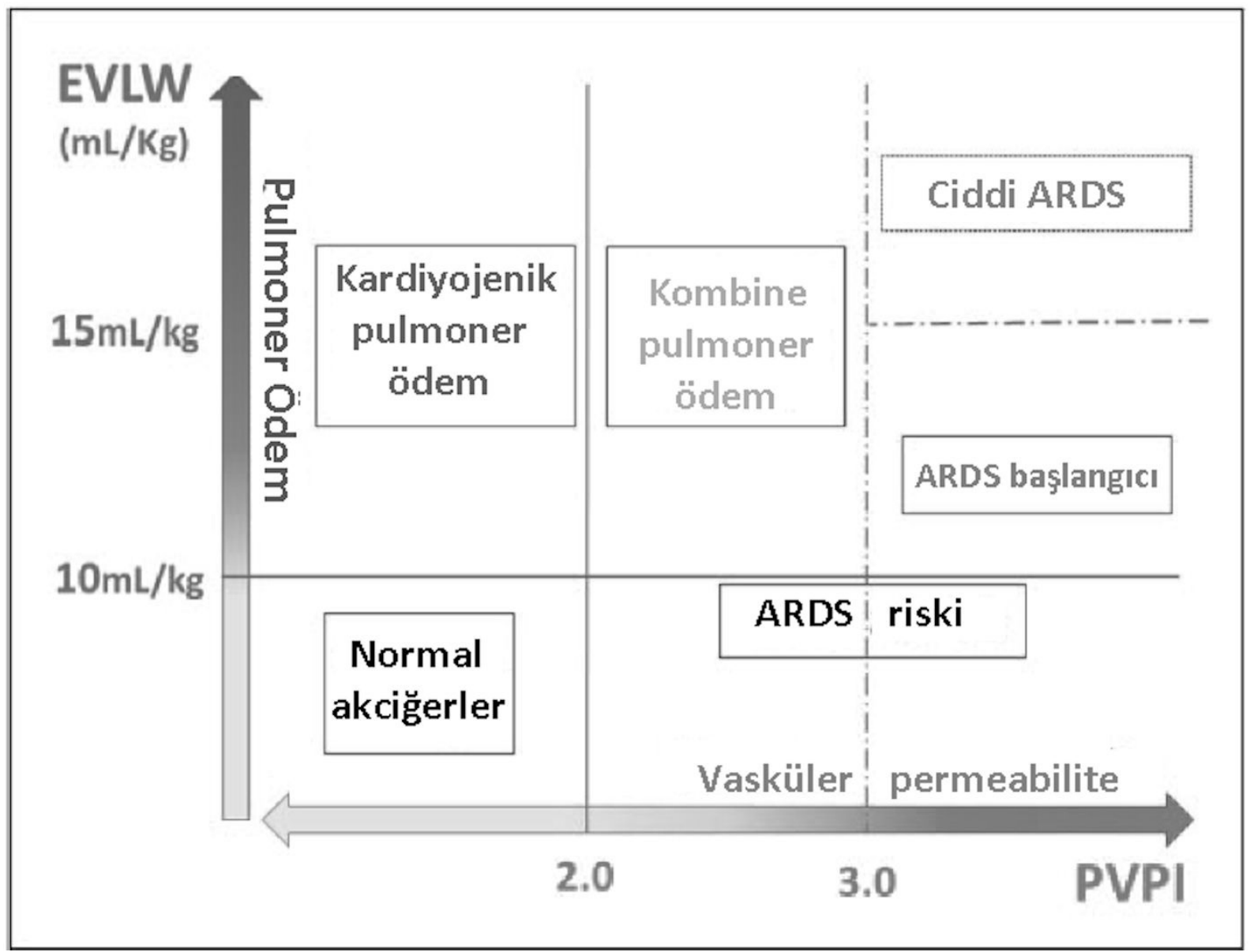

Figür 7. PVPI ve EVLW ilişkisi. Normal akciğerlerde EVLW<10 ve PVPI $<2$ 'dir. EVLW>10 iken $P V P I<2$ olması durumunda kardiyojenik pulmoner ödeme işaret eder. EVLW $>10$ olması pulmoner ödem için anlamlı kabul edilmekteyken eş zamanlı PVPI >2 olması artmış vasküler permeabiliteyi (ARDS) göstermektedir. PVPI >3 iken EVLW 10-15 aralığında ise ARDS başlangıcı, EVLW>15 olması durumunda ise ciddi ARDS'den söz edilebilir.

filtrasyon ile azaltılmasının total vücut sıvısını azalttığı, oksijenizasyonu ve pulmoner kompliyansı iyileştirdiği gösterilmiştir.

\section{ii. Toraks cerrahisi}

Toraks cerrahisinde damar dışı akciğer sıvısının ölçümü, akciğer ödemi tanı ve tedavisinin yönlendirilmesinde ve sonuçların erken öngörülmesinde yararlıdır. Perioperatif dönemde EVLW takibi klinisyenlere bu hastalarda SıVı yönetimi ve akciğer transplantasyonunda donör seçiminde de yarar sağlamaktadır. Akciğer donörü olarak takip edilen, beyin ölümü gerçekleşmiş hastalarda EVLW değerinin <10 ml/kg olmasının akciğer transplantasyonu için uygunluğu öngördüğü bildirilmektedir ${ }^{[7]}$. Akciğer transplantas- yonu sonrasında hastaların yaklaşık \%10'unda görülen primer graft disfonksiyonu, ARDS benzeri klinik ve patolojik bir tablo oluşturur. EVLW'de yükselmenin erken dönemde saptanması, klinisyenleri akciğer koruyucu ventilasyon, inhale nitrik oksit tedavisi, veya ekstrakorporeal membran oksijenizasyonu gibi tedavilere hızlı başlanması konusunda uyarabilir[7].

Buna ek olarak, minör akciğer rezeksiyonu geçiren 40 hasta üzerinde gerçekleştirilen bir çalışmada, normovolemi ve akciğer koruyucu ventilasyonun EVLW'yi yükseltmediği bulunmuş ve akciğer rezeksiyonlarında EVLW ile sıVı yönetiminin postoperatif dönemde pulmoner ve ekstrapulmoner komplikasyonları engellemede avantaj sağlayacağı belirtilmiştir ${ }^{[40]}$. 
Termodilüsyon yöntemiyle EVLW ölçümü sıvı yönetimine ek olarak yüksek riskli hastalarda akciğer rezeksiyonu sonrası pulmoner ödem tedavisinde salbutamolun etkinliğinin izlenmesinde ${ }^{[41]}$ ve hayvan modelinde akciğer transplantasyonu sonrası graft yetmezliğinin engellenmesinde sildenafil uygulamasının takibinde ${ }^{[42]}$ de kullanılmıştır. Özofajektomi hastalarında da, cerrahiden sonraki 12 saatte EVLW yüksekliğinin bozulmuş postoperatif oksijenizasyon ile ilişkili olduğu gösterilmiştir ${ }^{[43]}$.

\section{iii. Abdominal cerrahi}

Yüksek riskli abdominal cerrahide intraoperatif ve postoperatif dönemde hedefe yönelik tedavi ve sIVI optimizasyonu için ileri hemodinamik monitörizasyon yöntemlerinden biri olan termodilüsyon metodu ile EVLW ölçümü, pulmoner ödemin ciddiyeti ve seyri hakkında bilgi verir. EVLW ve PVPI'ın birlikte değerlendirilmesi, pulmoner ödemin hidrostatik veya permeabilite artışına bağlı olup olmadığı konusunda klinisyeni yönlendirerek sonuçların iyileştirilmesine katkı sağlar. Calvo ve ark.'nın ${ }^{[44]}$ majör abdominal cerrahi sonrası noninvazif mekanik ventilasyon uygulanan 99 hastanın verilerini retrospektif olarak değerlendirdiğ i çalışmasında, tedavi etkinliği EVLW ve PVPI kullanılarak değerlendirilmiş ve EVLWI için 9,5 ve PVPI için 2.45 ve altında olmasının noninvazif mekanik ventilasyonun başarısı için prediktif olduğu belirtilmiştir.

Kardiyak ve pulmoner komplikasyon sıklığının yüksek olması nedeniyle yüksek riskli bir cerrahi olarak tanımlanan ortotopik karaciğer transplantasyonunda da EVLW ve PVPI ölçümü ile postoperatif uzamış mekanik ventilasyonun öngörülebilmesi amacıyla yapılmış bir çalışmada, EVLW>12 ve PVPI>2.3 olması durumunda hastaların yaklaşık \%13'ünde 48 saatten uzun süren mekanik ventilasyon gereksinimi olduğu ve hastanede yatışı ortalama 5 gün uzattığ gözlenmiştir ${ }^{[45]}$

\section{v. Yanıklar}

Majör yanıklarda tedavi hedefleri hipovoleminin önlenmesi ve etkin perfüzyonun sağlanmasıdır. Yanıklı hastalarda aşırı sıvı tedavisinin interstisyel sıvı birikimi, pulmoner ödem, abdominal kompartman sendromu ve yara iyileşmesinde gecikme gibi yan etkileri olduğundan, intraoperatif ve postoperatif dönemde SIVI dengesinin yakın takibi önemlidir. İdeal resusitasyon, yalnızca hipovoleminin düzeltilmesi değil, aynı zamanda aşırı sıvı yükünden kaçınmaktır. Yanık şokunun resusitasyonunda monitörizasyon geleneksel kalp hızı, kan basıncı, santral venöz basınç ve idrar çıkımının monitörizasyonundan Swan Ganz kateterizasyonu, özofageal Doppler ekokardiografi ve TPTD yöntemiyle EVLW takibi kavramlarına yönelmiştir ${ }^{[46]}$.

Ciddi yanığı olan 121 hasta üzerinde gerçekleştirilen retrospektif bir çalışmada, yanıktan sora gelişen ARDS kliniğinde 2. gün EVLW değerlerinde 1.6 $\pm 1,5$ $\mathrm{ml} / \mathrm{kg}$ düşüş olmasının artmış sağ kalım şansı ile ilişkili olduğu gösterilmiştir ${ }^{[47]}$.

Yanıklı hastalarda, morbidite ve mortalitenin en önemli nedenlerinden olan sepsis ve çoklu organ yetmezliğinde EVLW'nin prediktif değerinin incelendiği 28 hasta üzerinde yapılan bir araştırmada, EVLWI değerlerinin yanığın gerçekleştiği günde prokalsitonin ve PEEP seviyeleri ile korele olduğu gösterilmiştir. Benzer şekilde enfeksiyon teşhisinden 1 gün önce EVLW değerlerinin anlamlı şekilde yükseldiği gözlenmiştir. Sepsis kliniğinden 1 gün önce EVLWI>9 ml/kg olmasının sepsis tanısı için \%89 sensitivite, \%72 spesifite gösterdiği belirtilmiştir. Antibiyotik tedavisi sonrasında sağ kalanlarda EVLW değerleri düşerken prokalsitoninde anlamlı bir değişiklik gözlenmemiştir ${ }^{[48]}$.

\section{TPTD ile EVLW ölçümünü etkileyen faktörler}

\section{i. Pulmoner vasküler oklüzyon}

Büyük pulmoner damarların oklüzyonu durumunda soğuk indikatör tüm akciğer alanlarına ulaşamadığından EVLW yanlış düşük ölçülebilir. Klinik olarak bu durum büyük pulmoner embolilerde EVLW'nin düşük ölçülmesine neden olabilir ${ }^{[49]}$.

\section{ii. Akciğer rezeksiyonu}

Akciğer rezeksiyonunda EVLW değerlerinde azalma 
beklenir ve yapılan deneysel çalışmalarda da pnömonektomi sonrasında termodilüsyon yöntemi ile ölçülen EVLW değerlerinin azaldığı gösterilmiştir ${ }^{[50]}$.

Tek akciğer ventilasyonunda termodilüsyon yöntemi ile EVLW ölçümü ciddi oranda etkilenir. 23 domuz üzerinde yapılan bir çalışmada, tek akciğer ventilasyonunun hem normovolemi hem de hipovolemi durumunda EVLWI değerlerinde azalmaya neden olduğu gösterilmiştir ${ }^{[51]}$. Pnömonektomi geçiren veya tek akciğer ventilasyonu yapılan ARDS hastalarında termodilüsyon ile elde edilen EVLW değerlerinin dikkatli değerlendirilmesi gerekir, bu nedenle EVLW değerlerindeki değişimler ( $\triangle \mathrm{EVLW}$ ) daha güvenilir kabul edilmektedir ${ }^{[49]}$.

\section{iii. ARDS türleri}

Deneysel çalışmalarda, homojen akciğer hasarı durumlarında termodilüsyon ile yapılan EVLW ölçümlerinin etkilenmediği, heterojen hasar durumlarında ise düşük ölçüldüğü belirtilmiş ve bunun nedeni olarak da pulmoner kan akımının ödemli alanlardan redistribüsyonu gösterilmiştir ${ }^{[52]}$.

Bununla birlikte, Schuster ve ark. ${ }^{[53]}$ ALI/ARDS hastalarında, rejyonel pulmoner perfüzyonda değişiklik olmadığını ve sağlıklı kişilerde bulunan hipoksik vazokonstriksiyon mekanizmasının bu hastalarda bozulduğunu pozitron emisyon tekniği ile göstermiştir. Sonuç olarak, ALI/ARDS hastalarında termodilüsyon tekniğinin güvenilir olduğu söylenebilir.

\section{iv. PEEP}

PEEP uygulamasının EVLW üzerine karmaşık etkileri vardır. PEEP, soğuk indikatörün dağıldığı hacim üzerindeki etkileri nedeniyle TPTD tekniğinin güvenilirliğini etkileyebilir. Yüksek PEEP seviyeleri pulmoner mikrovasküler yapıyı sıkıştırarak indikatörün dağıldığı hacmi azaltabilir ve yanlış düşük ölçümlere neden olabilir. Diğer yandan yüksek PEEP seviyeleri atelektazileri açarak ve hipoksik vazokonstriksiyonu ortadan kaldırarak indikatörün dağılım hacmini arttırabilir ve böylelikle yüksek ölçümlere neden olabilir ${ }^{[54]}$.
Bunlara ek olarak, PEEP uygulaması, kardiyak outputu düşürerek pulmoner mikrovasküler hidrostatik basıncı ve böylelikle EVLW miktarını azaltabilir. Benzer şekilde, hidrostatik pulmoner ödem durumunda PEEP hemodinamik etkileri sayesinde kardiyak fonksiyonu iyileştirerek EVLW değerlerini azaltabilir ${ }^{[55]}$. ARDS durumunda santral venöz basıncı arttırarak lenfatik drenajın azalmasına bağlı EVLW değerlerini yükseltebilir ${ }^{[56]}$.

ARDS hastaları üzerinde yapılan bir çalışmada, 10 ile $20 \mathrm{cmH}_{2} \mathrm{O}$ PEEP değerleri arasında transpulmoner termodilüsyon yöntemi ve bilgisayarlı tomografi ile hesaplanan akciğer ağırlığı arasında yakın bir korelasyon olduğu gösterilmiştir ${ }^{[20]}$. Bu durum, PEEP uygulamasının termodilüsyon yöntemi ile ölçülen EVLWI değerleri üzerine etkisinin savsaklanabilir olduğuna işaret etmektedir.

\section{v. Plevral efüzyon}

Plevral effüzyon durumunda, plevral sıvının soğuk bolusun dilüe olduğu hacmi arttırarak EVLWI değerlerinin yüksek ölçümüne neden olacağı düşünülmüştür. Bununla birlikte, plevral kavitedeki sıvı ve pulmoner damarlar arasındaki mesafe nedeniyle bu düşünceden uzaklaşılmıştır. Yakın zamanda yapılan bir çalışmada, yüksek hacimli torasentezin transpulmoner termodilüsyon ile ölçülen EVLWI değerlerinde azalmanın aksine bir artışa neden olduğu gösterilmiştir ${ }^{[57]}$. Bunun nedeni olarak, torasentez sonrasında atelektatik alanların açııması veya daha düşük bir olasılıkla da posttorasentez hidrostatik pulmoner ödem gelişimi gösterilebilir. Bu bilgiler ışığında plevral effüzyonun EVLW üzerine etkisi ile ilgili daha fazla çalışmasına gereksinim olduğu söylenebilir.

Renal replasman tedavisinde, ekstrakorporeal devredeki akım soğuk indikatörün kaybına neden olacak kadar yüksek olmadığından EVLW ölçümlerinin 300 $\mathrm{ml} / \mathrm{dk}$. gibi yüksek akımlarda bile etkilenmediği gösterilmiştir ${ }^{[58]}$.

Ekstrakorporeal membran oksijenizasyonunda termodilüsyon yöntemi güvenilirliğini kaybetmektedir. 
Terapötik hipotermi, soğuk bolus enjeksiyonunun kan sıcaklığı üzerindeki etkisini engellemediğinden dolayı termodilüsyon tekniğini etkilememektedir ${ }^{[59]}$.

Sonuç olarak, majör cerrahiler sırasında ve sonrasında EVLW ölçümü, postoperatif ARDS, pulmoner ödem ve akciğer graft disfonksiyonu gibi morbidite ve mortalite üzerine etkili konularda klinisyenler için bir erken uyarı sistemi olarak kullanılmakta ve sıvı yönetiminde yararlı bilgiler sunmaktadır. Gelecekte ARDS tanı kriterleri arasına girmesi planlanan EVLW aynı zamanda akciğer transplantasyonunda donör havuzunun genişletilmesinde de yararlı olacaktır. Ülkemiz şartlarında yüksek maliyet ve invaziv olması gibi kısıtlayıcılıklarına rağmen, TPTD yöntemi ile EVLW ölçümü postoperatif yoğun bakım takibi gerektiren cerrahilerde yukarıda belirtilen yararlarına ek olarak ileri hemodinamik monitorizasyon parametrelerini (PPV, SVV, CI) kullanmak amaçlı da kullanılabilir. Günümüzde, ultrasonografinin anestezi uygulamalarındaki yaygın kullanımı göz önünde bulundurulduğunda, TPTD yöntemine kıyasla gerçek zamanlı, sensitif ve düşük maliyetli olması gibi nedenlerle USG ile EVLW ölçümü de giderek yaygınlaşmaktadır. Tüm bu bilgiler ışığında majör cerrahilerde EVLW ölçümü üzerine yapılacak yeni çalışmalara gereksinim vardır ve bu çalışmalar özellikle ölçüm tekniklerini etkileyen konular üzerine odaklanmalıdır.

\section{KAYNAKLAR}

1. Miskovic A, Lumb AB. Postoperative pulmonary complications. Br J Anaesth. 2017;118:317-34. https://doi.org/10.1093/bja/aex002.

2. Canet J, Sabaté S, Mazo V, Gallart L, De Abreu MG, Belda J, et al. Development and validation of a score to predict postoperative respiratory failure in a multicentre European cohort. Eur J Anaesthesiol 2015;32:458.70. https://doi.org/10.1097/EJA.0000000000000223.

3. Yang CK, Teng A, Lee DY, Rose K. Pulmonary complications after major abdominal surgery: National Surgical Quality Improvement Program analysis. J Surg Res. 2015;198:441-9. https://doi.org/10.1016/j.jss.2015.03.028.

4. Fernandez-Bustamante A, Frendl G, Sprung J, Kor DJ, Subramaniam B, Ruiz RM, et al. Postoperative pulmonary complications, early mortality, and hospital stay following noncardiothoracic surgery: A multicenter study by the perioperative research network investiga- tors. JAMA Surg. 2017;152:157-66. https://doi.org/10.1001/jamasurg.2016.4065.

5. Assaad S, Shelley B, Perrino A. Transpulmonary Thermodilution: Its Role in Assessment of Lung Water and Pulmonary Edema. J Cardiothorac Vasc Anesth. 2017;31:1471-80. https://doi.org/10.1053/j.jvca.2017.02.018.

6. Assaad S, Kratzert WB, Shelley B, Friedman MB, Perrino A. Assessment of Pulmonary Edema: Principles and Practice. J Cardiothorac Vasc Anesth. 2018;32:901-14. https://doi.org/10.1053/j.jvca.2017.08.028.

7. Assaad S, Kratzert WB, Perrino AC. Extravascular lung water monitoring for thoracic and lung transplant surgeries. Curr Opin Anaesthesiol. 2019;32:29-38. https://doi.org/10.1097/ACO.0000000000000683.

8. Beurton A, Teboul JL, Monnet X. Transpulmonary thermodilution techniques in the haemodynamically unstable patient. Curr Opin Crit Care 2019;25:273-9. https://doi.org/10.1097/MCC.0000000000000608.

9. Eichhorn V, Goepfert MS, Eulenburg C, Malbrain MLNG, Reuter DA. Comparison of values in critically ill patients for global end-diastolic volume and extravascular lung water measured by transcardiopulmonary thermodilution: A metaanalysis of the literature. Med Intensiva 2012;36:467-74. https://doi.org/10.1016/j.medin.2011.11.014.

10. Tagami T, Ong MEH. Extravascular lung water measurements in acute respiratory distress syndrome: Why, how, and when? Curr Opin Crit Care 2018;24:209-15. https://doi.org/10.1097/MCC.0000000000000503.

11. Pearce ML, Yamashita J, Beazell J. Measurement of pulmonary edema. Circ Res. 1965;16:482-8. https://doi.org/10.1161/01.RES.16.5.482.

12. Rouby JJ, Puybasset L, Cluzel P, Richecoeur J, Lu Q, Grenier P. Regional distribution of gas and tissue in acute respiratory distress syndrome. II. Physiological correlations and definition of an ARDS severity score. Intensive Care Med. 2000;26:1046-56. https://doi.org/10.1007/s001340051317.

13. Lichtenstein D, Goldstein I, Mourgeon E, Cluzel P, Grenier P, Rouby JJ. Comparative diagnostic performances of auscultation, chest radiography, and lung ultrasonography in acute respiratory Distress Syndrome. Anesthesiology 2004;100:9-15. https://doi.org/10.1097/00000542-200401000-00006.

14. Cagini L, Andolfi M, Becattini C, Ranalli MG, Bartolucci $F$, Mancuso A, et al. Bedside sonography assessment of extravascular lung water increase after major pulmonary resection in non-small cell lung cancer patients. J Thorac Dis. 2018;10:4077-84. https://doi.org/10.21037/jtd.2018.06.130.

15. Picano E, Pellikka PA. Ultrasound of extravascular lung water: A new standard for pulmonary congestion. Eur Heart J 2016;37:2097-104. https://doi.org/10.1093/eurheartj/ehw164.

16. Mayo JR, MacKay AL, Whittall KP, Baile EM, Paré PD. Measurement of lung water content and pleural pressure gradient with magnetic resonance imaging. J Thorac Imaging 1995;10:73-81. https://doi.org/10.1097/00005382-199501010-00007.

17. Chow K, Toma M, Esch B, Scott J, Haykowsky M, Thompson R, et al. Comparison of MRI-derived pulmonary edema measures with LVEDP and serum BNP. J Cardiovasc Magn Reson 2009;11:P41. 
https://doi.org/10.1186/1532-429X-11-S1-P41.

18. Lancaster L, Bogdan AR, Kundel HL, McAffee B. Sodium MRI with coated magnetite: Measurement of extravascular lung water in rats. Magn Reson Med 1991;19:96104.

https://doi.org/10.1002/mrm.1910190109.

19. Kuzkov V V., Suborov E V., Kirov MY, WÆErhaug K, Mortensen R, Kuklin VN, et al. Radiographic lung density assessed by computed tomography is associated with extravascular lung water content. Acta Anaesthesiol Scand 2010;54:1018-26. https://doi. org/10.1111/j.1399-6576.2010.02272.x.

20. Patroniti N, Bellani G, Maggioni E, Manfio A, Marcora $B$, Pesenti A. Measurement of pulmonary edema in patients with acute respiratory distress syndrome. Crit Care Med 2005;33:2547-54.

https://doi.org/10.1097/01.CCM.0000186747.43540.25.

21. Scillia P, Delcroix M, Lejeune P, Mélot C, Struyven J, Naeije R, et al. Hydrostatic pulmonary edema: Evaluation with thin-section CT in dogs. Radiology 1999;211:161-8. https://doi.org/10.1148/radiology.211.1.r99ap07161.

22. Barile M, Hida T, Hammer M, Hatabu H. Simple quantitative chest CT for pulmonary edema. Eur J Radiol Open 2020;7. https://doi.org/10.1016/j.ejro.2020.100273.

23. Velazquez M, Haller J, Amundsen T, Schuster DP. Regional lung water measurements with PET: Accuracy, reproducibility, and linearity. J Nucl Med 1991;32:71925.

24. Schuster DP, Anderson C, Kozlowski J, Lange N. Regional pulmonary perfusion in patients with acute pulmonary edema. J Nucl Med 2002;43:863-70.

25. Schuster DP, Mintun MA, Green MA, Ter-Pogossian MM. Regional lung water and hematocrit determined by positron emission tomography. J Appl Physiol 1985;59:860-8. https://doi.org/10.1152/jappl.1985.59.3.860.

26. Pomerantz M, Delgado F, Eiseman B. Clinical evaluation of transthoracic electrical impedance as a guide to intrathoracic fluid volumes. Ann Surg 1970;171:68694. https://doi.org/10.1097/00000658-197005000-00007.

27. Becher J, Kaufmann SG, Paule S, Fahn B, Skerl O, Bauer WR, et al. Device-based impedance measurement is a useful and accurate tool for direct assessment of intrathoracic fluid accumulation in heart failure. Europace 2010;12:731-40.

https://doi.org/10.1093/europace/eup413.

28. Wang L, Lahtinen S, Lentz L, Rakow N, Kaszas C, Ruetz $L$, et al. Feasibility of using an implantable system to measure thoracic congestion in an ambulatory chronic heart failure canine model. PACE - Pacing Clin Electrophysiol 2005;28:404-11. https://doi.org/10.1111/j.1540-8159.2005.40009.x.

29. Yu CM, Wang L, Chau E, Chan RHW, Kong SL, Tang MO, et al. Intrathoracic impedance monitoring in patients with heart failure: Correlation with fluid status and feasibility of early warning preceding hospitalization. Circulation 2005;112:841-8. https://doi.org/10.1161/CIRCULATIONAHA.104.492207.

30. Lewis FR, Elings VB, Hill SL, Christensen JM. The measurement of extravascular lung water y thermal-green dye indicator dilution. Ann N Y Acad Sci 1982;384:394-
410.

https://doi.org/10.1111/j.1749-6632.1982.tb21388.x.

31. Dasta JF, McLaughlin TP, Mody SH, Piech CT. Daily cost of an intensive care unit day: The contribution of mechanical ventilation. Crit Care Med 2005;33:1266-71. https://doi.org/10.1097/01.CCM.0000164543.14619.00.

32. Naum A, Tuunanen $H$, Engblom E, Oikonen V, Sipilä $H$, Iozzo $P$, et al. Simultaneous evaluation of myocardial blood flow, cardiac function and lung water content using [15O]H2O and positron emission tomography. Eur J Nucl Med Mol Imaging 2007;34:563-72. https://doi.org/10.1007/s00259-006-0259-3.

33. Hopkins SR, Levin DL, Emami K, Kadlecek S, Yu J, Ishii $M$, et al. Advances in magnetic resonance imaging of lung physiology. J Appl Physiol 2007;102:1244-54. https://doi.org/10.1152/japplphysiol.00738.2006.

34. Kor DJ, Warner DO, Carter RE, Meade LA, Wilson GA, Li $\mathrm{M}$, et al. Extravascular lung water and pulmonary vascular permeability index as markers predictive of postoperative acute respiratory distress syndrome: A prospective cohort investigation. Crit Care Med 2015;43:665-73.

https://doi.org/10.1097/CCM.0000000000000765.

35. Verheij J, van Lingen A, Raijmakers PGHM, Rijnsburger ER, Veerman DP, Wisselink W, et al. Effect of fluid loading with saline or colloids on pulmonary permeability, oedema and lung injury score after cardiac and major vascular surgery. Br J Anaesth. 2006;96:21-30. https://doi.org/10.1093/bja/aei286.

36. Johan ABJ, Jansen EK, Verheij J. Mechanisms of pulmonary dysfunction after on-pump and off-pump cardiac surgery: A prospective cohort study. J Cardiothorac Surg. 2007;2. https://doi.org/10.1186/1749-8090-2-11.

37. Weissman C. Pulmonary complications after cardiac surgery. Semin. Cardiothorac. Vasc. Anesth., vol. 8, Semin Cardiothorac Vasc Anesth; 2004, p. 185-211. https://doi.org/10.1177/108925320400800303.

38. Verheij J, Van Lingen A, Raijmakers PGHM, Spijkstra JJ, Girbes ARJ, Jansen EK, et al. Pulmonary abnormalities after cardiac surgery are better explained by atelectasis than by increased permeability oedema. Acta Anaesthesiol Scand. 2005;49:1302-10. https://doi.org/10.1111/j.1399-6576.2005.00831.x.

39. Elayashy M, Madkour MA, Mahmoud AAA, Hosny $H$, Hussein A, Nabih A, et al. Effect of ultrafiltration on extravascular lung water assessed by lung ultrasound in children undergoing cardiac surgery: A randomized prospective study. BMC Anesthesiol. 2019;19. https://doi.org/10.1186/s12871-019-0771-1.

40. Assaad S, Kyriakides T, Tellides G, Kim AW, Perkal M, Perrino A. Extravascular lung water and tissue perfusion biomarkers after lung resection surgery under a normovolemic fluid Protocol. J Cardiothorac Vasc Anesth. 2015;29:977-83. https://doi.org/10.1053/j.jvca.2014.12.020.

41. Licker M, Tschopp JM, Robert J, Frey JG, Diaper J, Ellenberger $\mathrm{C}$. Aerosolized salbutamol accelerates the resolution of pulmonary edema after lung resection. Chest. 2008;133:845-52. https://doi.org/10.1378/chest.07-1710.

42. Korom S, Hillinger S, Cardell M, Zhai W, Tan Q, Dutly A, et al. Sildenafil extends survival and graft function in a large animal lung transplantation model. Eur. J. Cardio- 
thoracic Surg., vol. 29, Eur J Cardiothorac Surg; 2006, p. 288-93. https://doi.org/10.1016/j.ejcts.2005.12.023.

43. Sato $Y$, Motoyama S, Maruyama K, Okuyama M, Hayashi K, Nakae $\mathrm{H}$, et al. Extravascular lung water measured using single transpulmonary thermodilution reflects perioperative pulmonary edema induced by esophagectomy. Eur Surg Res. 2007;39:7-13. https://doi.org/10.1159/000096926.

44. Redondo Calvo FJ, Bejarano Ramirez N, Uña Orejon R, Villazala Garcia R, Yuste Peña AS, Belda FJ. La elevación del índice de agua pulmonar extravascular como factor predictivo del fracaso de la presión continua en la vía aérea con casco (CPAP-Helmet) en pacientes con insuficiencia respiratoria aguda tras intervención quirúrgica mayor. Arch Bronconeumol. 2015;51:558-63. https://doi.org/10.1016/j.arbres.2015.01.012.

45. Garutti I, Sanz J, Olmedilla L, Tranche I, Vilchez A, Fernandez-Quero L, et al. Extravascular lung water and pulmonary vascular permeability index measured at the end of surgery are independent predictors of prolonged mechanical ventilation in patients undergoing liver transplantation. Anesth. Analg., vol. 121, Lippincott Williams and Wilkins; 2015, p. 736-45. https://doi.org/10.1213/ANE.0000000000000875.

46. Gong C, Zhang F, Li L, He F, Liu GC, Zhu SH, et al. The variation of hemodynamic parameters through PiCCO in the early stage after severe burns. J Burn Care Res 2017;38:E966-72. https://doi.org/10.1097/BCR.0000000000000533.

47. Wang W, Xu N, Yu X, Zuo F, Liu J, Wang Y, et al. Changes of Extravascular Lung Water as an Independent Prognostic Factor for Early Developed ARDS in Severely Burned Patients. J Burn Care Res. 2020;41:402-8. https://doi.org/10.1093/jbcr/irz189.

48. Bognar Z, Foldi V, Rezman B, Bogar L, Csontos C. Extravascular lung water index as a sign of developing sepsis in burns. Burns 2010;36:1263-70. https://doi.org/10.1016/j.burns.2010.04.006.

49. Jozwiak M, Teboul JL, Monnet X. Extravascular lung water in critical care: recent advances and clinical applications. Ann Intensive Care 2015;5:1-13. https://doi.org/10.1186/s13613-015-0081-9.

50. Kuzkov V V., Suborov E V., Kirov MY, Kuklin VN, Sobhkhez M, Johnsen S, et al. Extravascular lung water after pneumonectomy and one-lung ventilation in sheep. Crit Care Med. 2007;35:1550-9. https://doi.org/10.1097/01.CCM.0000265739.51887.2B.
51. Haas SA, Trepte CJC, Nitzschke R, Jürgens TP, Goepfert $M S$, Goetz AE, et al. An assessment of global enddiastolic volume and extravascular lung water index during one-lung ventilation: Is transpulmonary thermodilution usable? Anesth Analg. 2013;117:83-90. https://doi.org/10.1213/ANE.0b013e31828f2c39.

52. Roch A, Michelet P, Lambert D, Delliaux S, Saby C, Perrin G, et al. Accuracy of the double indicator method for measurement of extravascular lung water depends on the type of acute lung injury. Crit Care Med. 2004;32:811-7. https://doi.org/10.1097/01.CCM.0000114831.59185.02.

53. Schuster DP, Stark T, Stephenson J, Royal H. Detecting lung injury in patients with pulmonary edema. Intensive Care Med. 2002;28:1246-53. https://doi.org/10.1007/s00134-002-1414-3.

54. Myers JC, Reilley TE, Cloutier CT. Effect of positive endexpiratory pressure on extravascular lung water in porcine acute respiratory failure. Crit Care Med. 1988;16:52-4. https://doi.org/10.1097/00003246-198801000-00010.

55. Mondéjar EF, Mata GV, Cárdenas A, Mansilla A, Cantalejo F, Rivera R. Ventilation with positive endexpiratory pressure reduces extravascular lung water and increases lymphatic flow in hydrostatic pulmonary edema. Crit Care Med. 1996;24:1562-7. https://doi.org/10.1097/00003246-199609000-00022.

56. Michard F. Bedside assessment of extravascular lung water by dilution methods: Temptations and pitfalls. Crit Care Med. 2007;35:1186-92. https://doi.org/10.1097/01.CCM.0000259539.49339.66.

57. Saugel B, Phillip V, Ernesti C, Messer M, Meidert AS, Schmid RM, et al. Impact of large-volume thoracentesis on transpulmonary thermodilution-derived extravascular lung water in medical intensive care unit patients. J Crit Care 2013;28:196-201. https://doi.org/10.1016/j.jcrc.2012.05.002.

58. Dufour N, Delville M, Teboul JL, Camous L, Favier Du Noyer A, Richard C, et al. Transpulmonary thermodilution measurements are not affected by continuous veno-venous hemofiltration at high blood pump flow. Intensive Care Med. 2012;38:1162-8. https://doi.org/10.1007/s00134-012-2573-5.

59. Tagami T, Kushimoto $S$, Tosa R, Omura M, Hagiwara J, Hirama $\mathrm{H}$, et al. The precision of $\mathrm{PiCCO}^{\circledR}$ measurements in hypothermic post-cardiac arrest patients. Anaesthesia 2012;67:236-43.

https://doi.org/10.1111/j.1365-2044.2011.06981.x. 